\title{
Effect of Blueberry Planting on Soil Habitat and Lake Basin
}

\author{
Xianhua $\mathrm{Wu}^{1}$, Yadong $\mathrm{Xue}^{2}$, Hong Chen ${ }^{1}$, Yue Wang ${ }^{1}$, Dandan Liu ${ }^{1}$ \\ ${ }^{1}$ Yuxi Research Center for Eco- environmental Sciences on Plateau Lakes, Yuxi Normal University, Yuxi, \\ Yunnan, 653100, China \\ ${ }^{2}$ Department for the Sanitary Monitoring and Test, Yuxi center for disease Control and prevention, Yuxi, \\ Yunnan, 653100, China
}

Keywords: Fuxian Lake, Blueberry planting, Environmental influence.

\begin{abstract}
During the dry season in 2014 and the rainy season in 2015, conduct sampling monitoring to the the 2-year, 3-year, 4-year, 6-year period of uncultivated soils, traditional agriculture, newly planted Blue Star blueberry soils and YiJiu blueberry base in the north bank of Fuxian Lake, and the monitoring indicators include soil organic matter, total nitrogen, total phosphorus, $\mathrm{Hg}, \mathrm{Zn}, \mathrm{Cd}, \mathrm{Pb}, \mathrm{Cr}$ and As. The monitoring results showed that there was a risk of heavy metal pollution in soils of different planting modes. The pollution risk of heavy metals in traditional agricultural soils was greater than that of blueberry soils. The main pollutants in blueberry soils were $\mathrm{Zn}$. The main pollutants in traditional agricultural soils were $\mathrm{Cd}, \mathrm{Pb}, \mathrm{Ni}$ and $\mathrm{Cu}$; the $\mathrm{TN}$ and $\mathrm{TP}$ concentrations in the surface runoff of blueberry plantation area were Grade B in GB18918-2002, the concentration of $\mathrm{Cr}$ and $\mathrm{Zn}$ in heavy metals was Grade I (GB3838-2002), the remaining heavy metals were not detected, and the water quality was better than the surface runoff in traditional agricultural areas. It was found through the Fuxian Lake sediments survey that sediment $\mathrm{Pb}, \mathrm{Zn}$ and $\mathrm{Cd}$ pollution levels have accelerated the trend.
\end{abstract}

\section{Field investigation}

In September 2014, the research team conducted on-the-spot investigation on the blueberry base of NiuMo Blue Star in the southwestern bank of Fuxian Lake, blueberry base in Star Village, and blue-eye of blue-eye rabbit in the Orange Garden of the village and stratified collection for submission. Among them, Niu Mula blue star blueberry base is in the state of preparation for planting, the site survey found that the organic fertilizer is mixed with grass, peat and so on, and added sulfur 15 days ago to adjust the $\mathrm{pH}$ of the soil; Star Village to be planted blueberries, at present The planting area is the original traditional agricultural soil in the Fuxianhu Valley; the star-shaped orange orchard has been planted with blue-eyed blueberry for three years and the planting area is seriously lacking in management with almost no yield. Soil survey data is shown in Table 1. It is suggested that the trend analysis of long-term development of blueberry planting on soil habitat of Bovine Blue Star Blueberry base and Star Village blueberry base is proposed.

Table 1. Soil Condition Survey Form for Blueberry Planting Base

\begin{tabular}{|c|c|c|c|c|c|c|}
\hline Sampling location & Depth cm & Moisture content(\%) & $\mathrm{PH}$ & EC(us) & Porosity & Note \\
\hline \multirow{12}{*}{$\begin{array}{l}\text { NiuMoLanXing Blueberry } \\
\text { Base }\end{array}$} & $0-10$ & 8.96 & 6.81 & 78.8 & \multirow{5}{*}{42.8} & \multirow{5}{*}{$\begin{array}{l}\text { 1\# planting zone first } \\
\text { planting }\end{array}$} \\
\hline & $10-20$ & 18.50 & 6.27 & 88.1 & & \\
\hline & $20-30$ & 18.14 & 6.57 & 75.4 & & \\
\hline & $30-40$ & 16.11 & 6.72 & 85.7 & & \\
\hline & $40-60$ & 16.62 & 6.78 & 84.2 & & \\
\hline & $0-10$ & 9.66 & 6.92 & 49.1 & \multirow{5}{*}{42.0} & \multirow{5}{*}{$\begin{array}{l}\text { 1\# planting zone first } \\
\text { planting }\end{array}$} \\
\hline & $10-20$ & 16.69 & 6.92 & 45.7 & & \\
\hline & $20-30$ & 16.98 & 6.84 & 63.8 & & \\
\hline & $30-40$ & 18.55 & 6.67 & 113.3 & & \\
\hline & $40-60$ & 18.47 & 6.93 & 36.1 & & \\
\hline & surface layer & 7.55 & 6.21 & 80.1 & 49.5 & No planting \\
\hline & surface layer & 31.61 & 6.73 & 877 & - & Soil under improvement \\
\hline Star Village & surface layer & 4.96 & 6.48 & 40.3 & - & Original soil \\
\hline Star Orange Garden & surface layer & 7.00 & 6.30 & 75.8 & 48.1 & $\begin{array}{l}3 \text { years’ planting; no } \\
\text { good management }\end{array}$ \\
\hline
\end{tabular}


The research team also sampled and monitored 2-year, 3-year, 4-year and 6-year blueberry soils grown in the old base of blue-collar north bank of Fuxian Lake. The soil survey data are shown in Table 2. The task force suggested that this base could be used as a comparative study of the impact of blueberry cultivation and traditional farming on soil habitats and lake basins.

The survey data in Table 1 and Table 2 show that the native soil $\mathrm{pH}$ in the Fuxian Lake Basin is 6.5-6.9, which is higher than the suitable $\mathrm{pH}$ range for blueberry growth. Within the range of $0-60 \mathrm{~cm}$ in the areas of NiuMoLanXing \# 1 and \# 2, the soil $\mathrm{pH}$ value is distributed in descending order. The soil in the range of $0-10 \mathrm{~cm}$ is affected by man-made stampede and long-time raining, Dense, slightly higher $\mathrm{pH}$, soil $\mathrm{pH}$ below $10 \mathrm{~cm}$ slightly lower, moisture content increased. The conductivity of organic fertilizer improved area reached 877us, more than 10 times that of other areas, probably due to pig manure and grass charcoal carrying a large amount of soluble ion precipitation. The increase of anion and cation concentration led to the increase of conductivity. Soil improvement affects the acid-base balance of native soil to a certain degree and leads to certain ecological risk. The YiJiu blueberry base soil loose and moist, good ventilation, blueberries grow well, long-term blueberry planting has changed the status of soil acidity, soil $\mathrm{pH}$ value of $60 \mathrm{~cm}$ has reached 5.4-5.43.

Table 2. Soil Condition Survey Form for Blueberry Planting Base

\begin{tabular}{|c|c|c|c|c|c|c|}
\hline Sampling location & Depth cm & $\begin{array}{c}\text { Moisture } \\
\text { content(\%) }\end{array}$ & $\mathrm{PH}$ & EC(us) & Porosity & Note \\
\hline \multirow{12}{*}{$\begin{array}{l}\text { YiJiu Blue Berry } \\
\text { Base }\end{array}$} & $0-10$ & 7.34 & 5.42 & 58.4 & \multirow{12}{*}{45.6} & \multirow{3}{*}{2 years' period } \\
\hline & $20-40$ & 20.14 & 5.43 & 47.6 & & \\
\hline & $40-60$ & 18.46 & 5.42 & 49.9 & & \\
\hline & $0-20$ & 14.14 & 5.43 & 25.2 & & \multirow{3}{*}{3 years' period } \\
\hline & $20-40$ & 18.79 & 5.43 & 41.00 & & \\
\hline & $40-60$ & 22.65 & 5.43 & 30.09 & & \\
\hline & $0-20$ & 13.36 & 5.40 & 13.36 & & \multirow{3}{*}{4 years' period } \\
\hline & $20-40$ & 13.96 & 5.40 & 13.93 & & \\
\hline & $40-60$ & 17.57 & 5.43 & 17.57 & & \\
\hline & $0-20$ & 10.63 & 5.39 & 130.70 & & \multirow{3}{*}{6 years' period } \\
\hline & $20-40$ & 19.22 & 5.43 & 29.95 & & \\
\hline & $40-60$ & 17.37 & 5.43 & 27.05 & & \\
\hline
\end{tabular}

\section{Environmental impact analysis}

Due to the soil acid-base and organic matter in the blueberry cultivation area, the soil in the blueberry planting area generally reduces the $\mathrm{pH}$ value and increases the salt content. Soil acidity and alkalinity ( $\mathrm{pH}$ value) is an important factor that affects the existing forms and adsorption capacity of heavy metals in soils. Acidic soils easily lead to the analysis of heavy metals in soils. Therefore, the blueberry cultivation should focus on the environmental impact of heavy metal pollution and organic matter, nitrogen Phosphorus loss problem.

\subsection{Evaluation of heavy metal background in soil}

In October 2014, the research team set up sampling points in the base of Niobium Blue Base on the southwestern bank of Fuxian Lake, blueberry plantation of Erjiacun in the north bank, old blueberry plantation, blueberry plantation in Zuoyulue Village, The contents of $\mathrm{Cd}, \mathrm{Hg}, \mathrm{As}, \mathrm{Cr}$ and $\mathrm{Cu}$ in soils were determined by HF-HNO3-HCLO4 triacid desalting, ICP-ACE or ion chromatography.

The determination of the total soil zinc content in the $100-166 \mathrm{mg} / \mathrm{kg}$ between the soil total lead content of $17-21 \mathrm{mg} / \mathrm{kg}$, soil total mercury content of $0.08-0.19 \mathrm{mg} / \mathrm{kg}$, the total soil chromium content of $51-95 \mathrm{mg} / \mathrm{kg}$, total soil cadmium content between $0.14-0.57 \mathrm{mg} / \mathrm{kg}$, total soil arsenic content between 7-18mg / kg, are in soil environmental quality standards (GB15618-1995) a and two Level standard range.

\subsection{Heavy metals evaluation in lake sediments}


The sources and pollution history of heavy metals in Fuxian Lake adopt 137Cs to count the sedimentary cores, and the heavy metal pollution in Fuxian Lake is evaluated by Geological Cumulative Index. Gravity sampler was used to obtain $31 \mathrm{~cm}$ and $26 \mathrm{~cm}$ column cores in the northern part of Fuxian Lake and the middle part of Fuxian Lake. According to the 137Cs dating of the core, 137Cs of the FB core sediments have two obvious Peak, indicating that the sedimentary environment is stable, without obvious interference.

According to the pollution degree grading method proposed by Milller, the influence of watershed on heavy metals in Fuxian Lake was as follows: the accumulation index of $\mathrm{Cd}$ at $1 \mathrm{~cm}, 3 \mathrm{~cm}$ and $5 \mathrm{~cm}$ in core of north of the lake (FB) were 1.87, 2.59 and 3.17 respectively, which had reached the intensity of pollution; $\mathrm{Cu}$ is non-polluting to moderately polluting; $\mathrm{Pb}$ and $\mathrm{Zn}$ are non-polluting below $7 \mathrm{~cm}$, non-polluting to moderately polluting above $7 \mathrm{~cm}$, and pollution index is increasing gradually; Cr below $13 \mathrm{~cm}$ is non-polluting and above $11 \mathrm{~cm}$ is non-polluting to moderate Pollution. The accumulation index of $\mathrm{Cd}$ at $2 \mathrm{~cm}$ and $4 \mathrm{~cm}$ in core of FZ was 2.20 and 2.63, respectively, moderate to strong pollution; $\mathrm{Pb}, \mathrm{Cr}$ and $\mathrm{Cu}$ were non-polluting; $\mathrm{Zn}$ below $5 \mathrm{~cm}$ was non-polluting and pollution index above $5 \mathrm{~cm}$ gradually increased Large, no pollution to moderate pollution.

\subsection{Evaluation of organic matter and nitrogen and phosphorus content in the soil}

Soil organic matter was determined by potassium cadmium potassium volumetric method. Soil total phosphorus was determined by acid-soluble molybdenum-antimony colorimetric method. Soil total nitrogen was determined by Kjeldahl distillation. The results showed that the content of organic matter in the blueberry plantation ranged from 10.19 to $28.01 \mathrm{~g} / \mathrm{kg}$, total phosphorus content between $0.9-6.7 \mathrm{~g} / \mathrm{kg}$, total nitrogen content between $0.4-1.7 \mathrm{~g} / \mathrm{kg}$. According to the second national soil census nutrition classification standards, blueberry plantation organic matter content of four five; total nitrogen content of six, total phosphorus content of a.

\subsection{Problem of heavy metals, organic matter and nitrogen and phosphorus loss in the soil}

The group selected two blueberry plantations to carry out soil heavy metals, organic matter and nitrogen and phosphorus loss problems, one located in the southwestern Fuxian Lake cattle blue star blueberry planting base, and the other is Fuxian Lake northeast coast of old blueberry planting base Within 2 years, 3 years, 4 years, 6 years age block.

During the dry seasons in 2014 and the rainy seasons in 2015, the research group studied the changes of soil organic matter, total nitrogen, total phosphorus, Hg in the blueberry planting area of the northernmost part of Fuxian Lake and the traditional agricultural (pea) , Zn, Cd, Pb, Cr and As to carry out sampling and monitoring in order to preliminary study on the impact of blueberry planting on soil habitat and lake basin.

\subsubsection{Organic Matter, Total Nitrogen, Total Phosphorus, $\mathrm{Hg}, \mathrm{Zn}, \mathrm{Cd}, \mathrm{Pb}, \mathrm{Cr}$ and As in Soil of NiuMo Blueberry Base and Pea Cultivation Area on the Southwest Bank of Fuxian Lake}

NiuMo Blueberry Base and Pea Cultivation Area on the Southwest Bank of Fuxian Lake was the in the construction period, and the land was deep matured and land preparation stage was completed. In order to facilitate the introduction and cultivation of blueberry, the soil needed to be improved. The results showed that: (1)The organic matter and total nitrogen of the base soil were higher than those of pea, while the total phosphorus value was lower than that of pea. The introduction of blueberry was beneficial to the reduction of surface phosphorus. (2) The contents of organic matter, total nitrogen and total phosphorus were higher than those of rainy season in dry season, Total nitrogen, total phosphorus loss, there are non-point source pollution Fuxian hidden dangers.

The results showed that $\mathrm{Cd}$ content in soil was second grade of soil environmental quality standard (GB15618-1995), and the dry season was longer than that of rainy season, indicating that Cd in blueberry soil was not easy to be lost. Pea The content of Cd in soils is twice as much as the third grade of soil environmental quality standard (GB15618-1995), and it is not easy to be lost. Therefore, the Cd content in peas soil should be highly valued by relevant departments.

The results of monitoring the content of heavy metals $\mathrm{Pd}$ and $\mathrm{Cr}$ in the blueberry base in the 
southwest of Fuxian Lake showed that the content of Pd in the base of the milk blueberry and pea was second level of the soil environmental quality standard (GB15618-1995), While pea in the Pd is easy to lose, which is different with the two kinds of plant fertilizers.

The results of monitoring the contents of heavy metal as in the blueberry base in the southwest of Fuxian Lake showed that the as content in the base of the milk blueberry and pea is higher than that of the soil environmental quality standard (GB15618-1995), and there is no hidden danger of heavy metal as pollution.

\subsubsection{Contents of soil organic matter, total nitrogen, total phosphorus, $\mathrm{Hg}, \mathrm{Zn}, \mathrm{Cd}, \mathrm{Pb}, \mathrm{Cr}$ and As in YiJiu blueberry base in the north bank Fuxian Lake}

Blueberries grow well in YiJiu blueberry base in the north bank Fuxian Lake. The tree ages were 2 years, 3 years, 4 years and 6 years. Compared with the monitoring data of organic matter and total nitrogen in the soils of newly-built NiuMo blueberry base and pea, the content is lower, indicating that blueberry planting with less pollution, less fertilizer, Yuxi Municipal Party Committee and municipal government planted blueberry as the adjustment of industrial structure of river basin, reduce Fuxian Lake non-point source pollution sources, to protect Fuxian Lake The important move is correct.

The Hg content in YiJiu blueberry base in the north bank Fuxian Lake showed that the content of $\mathrm{Hg}$ in the blueberry base soil was in the second grade of soil environmental quality standard (GB15618-1995), while the NiuMo base in the southwest of Fuxian Lake is grade 1. It is suggested that monitoring of $\mathrm{Hg}$ content in blueberry base and traditional agriculture and fertilizers should be strengthened to further clarify the background value and source of heavy metal $\mathrm{Hg}$ in soil in Fuxian Lake watershed.

The content of heavy metal Zn in YiJiu blueberry base in the north bank Fuxian Lake showed that the content of $\mathrm{Zn}$ in the base of blueberry was second grade of soil environmental quality standard (GB15618-1995), while the content of heavy metal Zn the NiuMo base in the southwest of Fuxian Lake was first grade. It is suggested to strengthen the monitoring of Hg content in the old blueberry base and nearby traditional agriculture and fertilizers, to further clarify the background value and source of heavy metal $\mathrm{Hg}$ in soils in different regions of Fuxian Lake, Increased content to make scientific judgments.

Monitoring of heavy metal Cd content in YiJiu blueberry base in the north bank Fuxian Lake showed that the content of $\mathrm{Cd}$ in soils of blueberry base soil was second level of soil environmental quality standard (GB15618-1995), while the content of heavy metal Cd in the NiuMo base in the southwest of Fuxian Lake was second level, and the content of $\mathrm{Cd}$ in the pea of south bank is more than twice that of the third grade of the soil environmental quality standard (GB15618-1995), and it is still not easy to lose. It is suggested to strengthen the determination of $\mathrm{Cd}$ in pea soil and other types of traditional agricultural soil.

The content of Pd in YiJiu blueberry base in the north bank Fuxian Lake exceeded the standard of soil environmental quality (GB15618-1995). The content of Pd in newly-built NiuMo blueberry base and pea in southwest bank was two Level, the northern coast of the old blueberry base of heavy metals over the Southwest Bank of blueberries and peas about 10 times, it is proposed to further clarify the Fuxianhu heavy metals in different regions of the background and sources of heavy metals in the blueberry Fuxian Lake Basin to plant whether the belt To increase the Pd content to make scientific judgments.

The content of As in the base of YiJiu blueberry base in the north bank Fuxian Lake showed that the content of As in the base of old blueberry was Grade II of soil environmental quality standard (GB15618-1995), and the content of Cr compared to newly-built NiuMo blueberry base and pea in southwest bank, it is recommended to strengthen the Fuxianhu heavy metals in different regions of the soil background value and source of investigation, especially blueberry cultivation of fertilizer application.

2.4.3 Nitrogen, Phosphorus and Heavy Metal Contents in Surface Water of NiuMo blueberry base in southwest bank of Fuxian Lake 
The temporal and spatial variations of TN and TP from the upstream ditch of NiuMo base through the NiuMo base to the downstream NiuMo wetland show that the concentrations of TN and TP in the water flowing through the plantation are higher than those in the park inlet and the wetland outlet, The dry season is greater than the rainy season, indicating that there are some nitrogen and phosphorus plantation release, but the concentration values are in GB18918-2002 a B, wetland water N, P concentration value of GB18918-2002.

Due to the lack of water in the ditches during the dry season, the research team monitored the heavy metals in the rainy seasons, and the concentrations of lead, cadmium, arsenic and mercury were not detected, but the trends of chromium and zinc concentrations gradually decreased. Class I of GB 3838-2002 at the outlet, class II at the base of blueberry and class I at the outlet of the wetland. The zinc concentration at the entrance and at the exit of the blueberry base is class I.

\section{Conclusions and suggestions}

\subsection{Conclusions}

(1)Before the 1980s, the heavy metals in the sediments of Fuxian Lake were dominated by natural sources. After the 1980s, the heavy metals were affected by human activities. However, Cu, Ni, Ti, V, $\mathrm{Pb}$ and $\mathrm{Zn}$ in the central part of the lake and $\mathrm{Cu}, \mathrm{Ni}, \mathrm{Ti}, \mathrm{V}$ is still dominated by natural sources.

(2) $\mathrm{Pb}$ and $\mathrm{Zn}$ in the sediments from the northern lake are less than 1, which is pollution-free to moderate pollution; the accumulation index of $\mathrm{Cd}$ in the north is 3-4, up to the intensity of pollution; the Cd accumulation index in the middle is 2-3, Pollution.

(3) The pollution of $\mathrm{Pb}, \mathrm{Zn}$ and $\mathrm{Cd}$ in lake sediments tends to increase rapidly

(4) Soil organic matter, total nitrogen, total phosphorus and heavy metal contents of $\mathrm{Hg}, \mathrm{Zn}, \mathrm{Cd}$, $\mathrm{Pb}, \mathrm{Cr}$ and As all showed that the surface soil was larger than the bottom soil, which was originated from exogenous and applied pesticides, pesticides, fertilizers and organic fertilizers related.

(5) The concentrations of TN and TP in the surface water of blueberry plantation are Grade B B of GB18918-2002; the concentrations of $\mathrm{Cr}$ and $\mathrm{Zn}$ in surface water are Grade I (GB3838-2002), the remaining heavy metals are not detected, and the water quality is better than that of Fuxian Lake Water quality.

(6) Blueberry cultivation compared with traditional agriculture, blueberry planting with less overall pollution, less fertilizer, water pollution is small, and have high economic benefits, can be used as protection Fuxianhu basin industrial structure adjustment.

\subsection{Suggestions}

(1) Further investigate the background and sources of organic matter, total nitrogen, total phosphorus, $\mathrm{Hg}, \mathrm{Zn}, \mathrm{Cd}, \mathrm{Pb}, \mathrm{Cr}$ and As in the soils of Fuxian Lake Basin, and further evaluate the impact of different agricultural modes on Fuxian Lake.

(2) Strengthen the survey of heavy metals $\mathrm{Pb}, \mathrm{As}, \mathrm{Hg}, \mathrm{Zn}$ and $\mathrm{Cd}$ in the blueberry planting base and traditional agricultural planting soil, especially the investigation of heavy metal $\mathrm{Pb}$, and control the quality of fertilizers, pesticides and insecticides, and improve the fertilizer quality testing system.

(3) Study on the Migration and Transformation of Soil Phosphorus and Heavy Metals in Blueberry Base.

\section{Acknowledgement}

This research was financially supported by the Sponsored by Yunnan University Science and Technology Innovation Team Support Program (IRTSTYN201422).

\section{References}

[1] Xia Tianxiang, Li Wenchao. Soil nitrogen and phosphorus loss and accumulation in organic and conventional vegetable fields in the northern bank of Fuxian Lake, Chinese Journal of 
Eco-Agriculture, 2008, 16(3):560—564.

[2] Wang Xiaolei, Yang Hao, Ding Zhaoyuan, Yang Benjun, Zhang Mingli.Study on the Changes of Fuxin Lake Sedimentation Rate in Yunnan Province in Modern Times, Geographical Journal, 2011,11 (11):1551-1559. 